\title{
Factors Influencing Faculty Publication Performance: A Grounded Theory Analysis
}

\author{
Helen C. Fuentes* \\ College of Education, Eastern Samar State University, Borongan City, Philippines. \\ *Correspondence: hcaliwan@yahoo.com (Helen C. Fuentes, Assistant Professor, College of Education, Eastern Samar \\ State University, Borongan City, Philippines).
}

\begin{abstract}
The study's major goal was to develop a theoretical model for the elements that influence ESSU faculty members' publication performance. The following conclusions were drawn using the grounded theory technique of qualitative research and the theoretical sampling procedure in the deciding to involve a total of 16 participants: favorable research atmosphere defined by the availability of funding support for publication fee, publication incentive, availability of technical support service, low workload in instruction and administration; research exposure and peer influence; favorable attitude toward publication; and belief in the beneficial effects of publication are the factors that lead to high publication performance. An unfavorable research environment, lack of exposure to research or weak research background, and a negative attitude toward research and publishing research results are all variables that contribute to poor publication performance. Furthermore, faculty members with excellent publishing performance were acknowledged in the scientific world, and a strong research track record led to funding opportunities and peer reviewer positions in scientific journals. Fortunately, the faculty members' academic rank rose as a result of their high publication performance.
\end{abstract}

Keywords: Publication performance, Research, Grounded Theory, and Attitude toward publication.

\section{INTRODUCTION:}

Most studies defined publication performance as published research results evaluated by an external peer critic. Several studies have looked into the factors that influence research and publication success. Work-environment characteristics may affect both the quality and quantity of academics' publishing performance, according to a recent study. Management strategies, leadership, and psychological skills all have an impact on academics' writing productivity (Aboagye, 2021). Using the ACHIEVE Model, Sulistiowati et al. (2020); found that research performance is influenced by ability, clarity, aid, incentive, evaluation, validity, and environment.

The number of research outputs published is one of the metrics of research productivity and a major final output (MFO) for research performance. Some university professors in Eastern Visayas region have UniversePG I www.universepg.com published research articles in journals and publications indexed by Scopus and the Thomson-Reuters Institute for Scientific Information (ISI), while the majority has not. According to data from the Commission on Higher Education-Zonal Research Center of Region VIII, the number of peer-reviewed journal publications increased from 34 in 2006 to 41 in 2007. In 2008, it dropped to 38, then to 24 and 20 in 2009 and 2010 (Villalino et al., 2012). Since publiccation performance is one of the bases for promotion among faculty members in State Universities and Colleges (SUCs), the number of published research articles in peer-reviewed journals is increasing.

In Eastern Samar State University, there is no documented clear explanation yet why researchers do not publish research results. Also, there is no visual model that can identify and explain the factors that influences the publication performance of faculty 
members. Using the grounded theory technique of data generation, the researcher endeavored to fill this gap and generate theoretical model to attain its aim.

\section{Objectives of the Study}

The study determined the factors that influence the publication performance of faculty researchers. Specifically, it aimed to attain the following objecttives:

1) To define the factors influencing publication performance.

2) To generate theoretical model for factors influencing publication performance.

\section{MATERIALS AND METHODS:}

\section{Research Design}

This study is qualitative and using the grounded theory research method. This method allows a researcher to create a theory that explains the main issue of the people in a certain area and how that concern is resolved or processed. Grounded theory aims to construct theory using proof that has been collected and examined utilizing comparative analysis in a logical manner (Chun Tie, 2019). A grounded theory investigation does not usually start with a theory from which hypotheses are deduced. It all begins with a research question, and only anything which is relevant to the issue is permitted in the research process. Glaser, (2014) emphasized that in grounded theory studies "the data are not forced to fit into the theory"; rather the theory is inferred from the data. Moreover, this research method provides a natural theoretical fit (Hussien, 2014).

\section{Respondents}

Subjects of this study were faculty members of Eastern Samar State University- Main Campus. They were chosen through purposive sampling. Based on their publication, they were classified as high publication performance (HPP) and low publication performance (LPP) groups. In determining the respondents groups (HPP and LPP), only the number of publications in peer-reviewed journals for the period 2016 to 2020 was used as basis. The HPP group was composed of faculty members who had published at least 3 (combined total of indicators) copyrighted books, registered utility model or scientific articles in ISI-indexed or Scopus-listed or CHED recognized journals (regardless of class) in the last 5 years. On the other hand, the LPP group is composed of faculty members who had published below 3 (combined total of indicators) copyrighted books or scientific UniversePG I www.universepg.com articles in ISI-indexed or Scopus-listed or CHED recognized journals (regardless of class) in the last 5 years. Theoretical sampling procedure was used in determining sample size. In this sampling procedure, the number of respondents is not pre-determined. Data gathering continues until data reaches the saturation point, that is, the stage wherein further observations and interviews add little or nothing to the codes identified by the researcher (Vincze, 2010).

\section{Data Collection}

Data on the factors influencing publication performance were gathered through in-depth interview with the selected respondents. Before the interview, the respondents were asked to fill-in a questionnaire to determine their publication performance (which was verified online) and they were briefed on the nature and content of the study, they were also asked to sign an informed content for human subject form. For instances that the respondent is not available for face-to-face interview, exchange of online messages was done. Secondary data were also used like 1) memoranda relative to research; 2) excerpt from Board Resolution; 3) records of fund allocation for research; 4) annual report; and 6) research manual.

\section{Data Processing}

The constant comparative method was used in this study's data collection and analysis (Glaser and Holton, 2014). To enable data analysis, the recorded dialogue was transcribed verbatim and encoded in written documents following each interview. The grounded theory methodology advocated by Creswell, (2007) was utilized to evaluate interview transcripts. The researcher used open coding, axial coding, and selective coding. To rate the respondents' publication performance, the researcher adapts the Research Performance Indicators (RPI) weighted scale to assess the respondents' publishing performance utilized by Wassenaar, (2006); Mamun, (2021); and Villa-lino and Cagasan, (2012), as follows:

\begin{tabular}{|c|c|}
\hline Published Work & Points \\
\hline Books & 5 \\
\hline Edited Books & 1 \\
\hline New edition/revision of a book & 2 \\
\hline Articles in Peer-reviewed Journals & 2 \\
\hline Other publications & 1 \\
\hline
\end{tabular}

In case of multiple authorships, the respondent's points were distributed evenly by dividing the points to the number of authors. The average publication 
performance per year of the respondents was determined using the following formula:

$A P P R Y=\frac{\left(Y_{1}+Y_{2}+Y_{3}+Y_{4}+Y_{5}\right)+T C}{5}$

Where,

APPRY $=$ the average publication performance per respondent per year.

$\mathrm{Y}=$ Research Performance Indicator (RPI) weight scale per year from 2016 to 2020 .

$\mathrm{TC}=$ Total number of citations the publications received from the date it was published (2016 up to 2020).

\section{Ethical Consideration}

All participants were oriented about the particulars of the study with emphasis on the categorization of the participants as LPP and HPP. Involvement in the study is voluntary, and they can withdraw from the study without any consequences. The researcher guaranties the anonymity of participants. To ensure confidentiality, only the researcher has access to research data.

\section{RESULTS AND DISCUSSION:}

Factors Leading to High Publication Performance Analysis of the interview transcripts of respondents from the HPP group revealed 4themes presented in Table 1 which includes: 1) favorable research atmosphere; 2) research exposure and peer influence;
3) favorable attitude toward publication; and 4) belief in the beneficial effects of publication.

\section{Favorable research atmosphere}

A favorable research environment is defined as- 1) financing support for publishing fees; 2) Incentives for publishing; 3) accessible technical support services to aid researchers in gaining access to journals; 4) A light burden in teaching and administration.

\section{Research exposure and peer influence}

Faculty members having research backgrounds from their graduate studies were able to complete a research project and publish the findings. It was also shown that faculty members who belonged to colleges with senior faculty members who are actively engaged in research were able to publish in scientific publications owing to the existence of mentoring and peer influence. Furthermore, faculty members are more likely to perform research if they have collaborators in their academic groups or departments.

\section{A favorable attitude toward publication}

The requirements of publication did not deter faculty members who had good views regarding undertaking research and publishing results.

\section{Beliefs in the beneficial effects of publication}

It is feasible to say that faculty members who actively participate in research and publication have better academic rankings and are acknowledged in the scientific community.

Table 1: Summary of the factors leading to high publication performance.

\begin{tabular}{|c|c|c|}
\hline \multicolumn{2}{|c|}{ Factors Leading to HPP } & \multirow[t]{2}{*}{ Description } \\
\hline Themes & Sub-Themes & \\
\hline $\begin{array}{c}\text { Favorable research } \\
\text { atmosphere }\end{array}$ & $\begin{array}{l}\text { Funding support for } \\
\text { publication fee } \\
\text { Publication incentive } \\
\text { Available technical support } \\
\text { services which assist the } \\
\text { researcher in accessing } \\
\text { journals } \\
\text { Low workload in instruction } \\
\text { and administration. }\end{array}$ & $\begin{array}{l}\text { Three respondents revealed that the University's policy to } \\
\text { shoulder the publication fee inspire them to publish research } \\
\text { results. } \\
\text { Four respondents said that in the previous years they had } \\
\text { received incentive when their paper was published; somehow it } \\
\text { motivated them to engage again in paper publishing in the } \\
\text { present year. } \\
\text { Two respondents revealed that the technical assistance of the } \\
\text { RDSO staff enabled them to publish. } \\
\text { One respondent said that having low workload in instruction in } \\
\text { of the previous semesters enabled her to conduct research and } \\
\text { published the results. }\end{array}$ \\
\hline $\begin{array}{l}\text { Research exposure } \\
\text { and peer influence }\end{array}$ & & $\begin{array}{l}\text { Four respondents revealed that their exposure to research } \\
\text { during their graduate study aid them in conducting research } \\
\text { and publishing; also when their colleague published their } \\
\text { research works they also tend to published. }\end{array}$ \\
\hline
\end{tabular}




\begin{tabular}{|c|c|c|}
\hline $\begin{array}{c}\text { Favorable attitude } \\
\text { toward publishing }\end{array}$ & $\begin{array}{c}\text { Two respondents said that their interest in conducting research } \\
\text { and publishing is an internal factor that pushes them to publish } \\
\text { in journals. }\end{array}$ \\
\hline $\begin{array}{c}\text { Belief in the beneficial } \\
\text { effects of publication }\end{array}$ & Promotion & $\begin{array}{c}\text { Five respondents revealed that they were encouraged to publish } \\
\text { because publication is important for the elevation of academic } \\
\text { rank since each publication is given credit in the NBC } 461 .\end{array}$ \\
\hline
\end{tabular}

Factors Leading to Low Publication Performance

Table 2 presents the factors leading to LPP of the surveyed faculty members. As shown, it includes- 1) unfavorable research environment; 2) no exposure to research; and 3) negative attitude towards publicshing. Heavy workload in instruction and administration, as well as a lack of technical support, suggest an unfavorable research environment. The faculty members with limited or no research experience in their graduate study struggle to conduct and publish the research results. Furthermore, faculty members who attended institutions where there were no senior faculty members who served as mentors had low research publishing performance because they had no one to question about research and thus believed that their work was not of high enough quality to be published. Furthermore, when multiple criticisms and suggestions were made to their paper, faculty members who had a negative attitude toward research and publishing were readily discouraged.

Table 2: Summary of the factors leading to low publication performance.

\begin{tabular}{|c|c|c|}
\hline \multicolumn{2}{|c|}{ Factors Leading to HPP } & \multirow[t]{2}{*}{ Description } \\
\hline Themes & Sub-Themes & \\
\hline $\begin{array}{l}\text { Unfavourable } \\
\text { research } \\
\text { environment }\end{array}$ & $\begin{array}{l}\text { Unavailability of technical support } \\
\text { which assist the researcher in } \\
\text { accessing journals and preparing } \\
\text { publishable formats } \\
\text { High workload in instruction and } \\
\text { administration }\end{array}$ & $\begin{array}{l}\text { Six respondents revealed that they have hard time in } \\
\text { publishing as to which scientific journals to publish. } \\
\text { All of the faculty members in the LPP group said that } \\
\text { they were not able to write research papers for } \\
\text { publication because of high workload in instruction and } \\
\text { administrative functions. }\end{array}$ \\
\hline $\begin{array}{l}\text { No exposure to } \\
\text { research and peer } \\
\text { influence }\end{array}$ & & $\begin{array}{l}\text { Two respondents revealed that they have poor research } \\
\text { exposure during their undergraduate and graduate } \\
\text { studies. Also, they have no access to research mentors } \\
\text { and their peers in the college/departments are not } \\
\text { inclined to research publishing. }\end{array}$ \\
\hline $\begin{array}{l}\text { Negative attitude } \\
\text { towards publishing }\end{array}$ & & $\begin{array}{l}\text { Some respondents said that they feel discouraged upon } \\
\text { seeing their research paper having many comments } \\
\text { from the evaluator so they set them aside and focus on } \\
\text { other priorities. The rigors of publishing in refereed } \\
\text { journals also discouraged the in submitting their } \\
\text { papers. Few LPP respondents said they opted to } \\
\text { publish in local and international journals that do not } \\
\text { require the rigorous review process. }\end{array}$ \\
\hline
\end{tabular}

\section{The Theoretical Model for ESSU Publication Per-} formance

Following the analysis of the interview transcripts, a theoretical model (Fig 1) was created to highlight the elements that influence faculty members' publication success at ESSU-Main Campus. Research environment, research background, peer influence, and attitude and belief about publishing research results are all covered by the model. The characteristics that support and hinder responders in publishing research results were collected from these general factors that influenced ESSU faculty publication performance.
The factors that lead to high publication performance are a favorable research environment as defined by funding support, technical support service, and low workload in instruction and administration; exposure to research and peer influence; positive attitude toward publishing; and belief in the positive consequences of publishing. Low publication performance was caused by an adverse research environment described by the lack of technical assistance and a heavy workload in instruction and administration; no exposure to research; and a negative attitude toward publishing. Consequences are un- 
avoidable at any level (high or poor) of publication performance. The strength and weakness of the University's overall performance would be determined by these implications. The data suggest that faculty members can be productive in research publishing if they are in a conductive research environment. If the university wants faculty members to write more, it should examine their teaching work-loads and provide technical aid in journal search and preparing publishable reports. These findings are similar to the results in the paper Villalino, (2012).
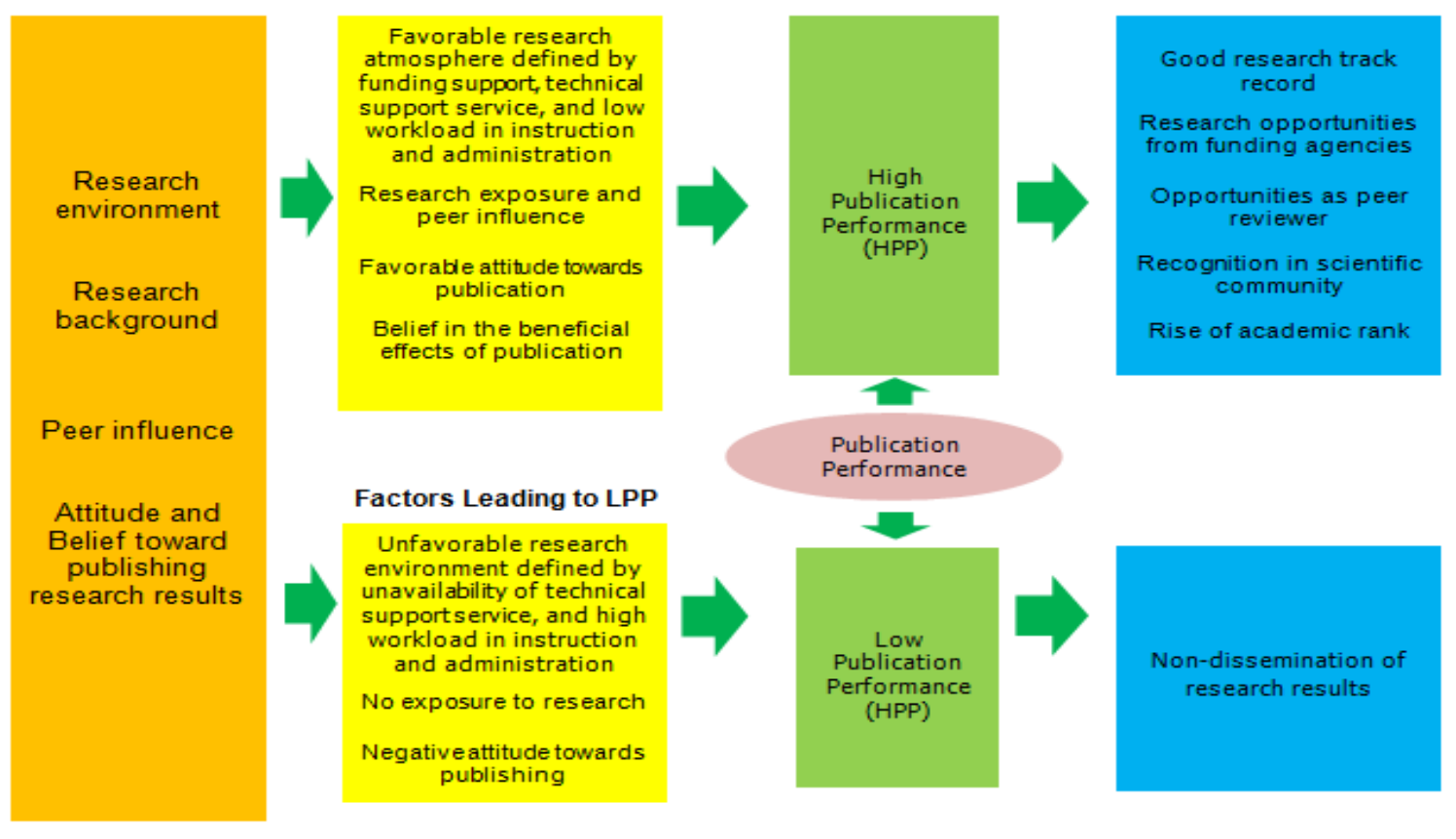

Fig 1: The theoretical model showing the factors influencing faculty publication performance Factors Leading to HPP Consequences.

\section{CONCLUSION:}

The findings and conclusion suggest that the factors leading to high publication performance include favorable research atmosphere defined by availability of funding support for publication fee, publication incentive, availability of technical support service, and low workload in instruction and supervision; research exposure and peer influence; favorable attitude towards publication; and belief in the beneficial effects of publication. The factors leading to low publication performance include unfavorable research atmosphere; no exposure to research and negative attitude towards publishing. Moreover, the University should devise/implement policies that the faculty researchers can conduct research while attending to their instruction Responsibilities. The University's Research Services Unit should include a full-time staff to help academic researchers in publishing research results. Finally, institutional support may be strengthened by providing faculty researchers with computing capabilities, facilities, and enough library resources, increasing money allocations for research initiatives, and balancing teaching and research workloads.

\section{ACKNOWLEDGEMENT:}

The author wishes to thank the faculty researchers for their cooperation during the in-depth interview.

\section{CONFLICTS OF INTEREST:}

The author declares there is no conflict of interest to publish it.

\section{REFERENCES:}

1) Aboagye, E., Jensen, I., et al. (2021). Investigating the association between publication performance and the work environment of university research academics: a systematic review. Scientomet, 126, 3283-3301. https://doi.org/10.1007/s11192-020-03820-y

2) Bitsch, V. (2005). Qualitative research: A grounded theory example and evaluation criteria. Journal of Agribusiness, 23(1), 75-91.

3) Creswell, J.W. (2018). Qualitative inquiry and research design: Choosing among five approaches. USA: Sage Publications. https://us.sagepub.com/en-us/nam/qualitativeinquiry-and-research-design/book246896

4) Glaser, B. G. (2004). Naturalist inquiry and 
grounded theory. Forum: Qualitative Social Research, 5(7).

https://granolagradschoolandgoffman.wordpress. com/2014/12/08/325/

5) Rahman M. (2021). Impact of socio-economic factors on undergraduate students' academic performance in Bangladesh: a case study at social science faculty, University of Dhaka, Asian J. Soc. Sci. Leg. Stud., 3(4), 147-157. https://doi.org/10.34104/ajssls.021.01470157

6) Sulistiowati, Sulistiowati \& Komari, Nurul. (2020). ACHIEVE Model on Research and Publication Performance. GATR Global J. of Business Social Sciences Review. 8, 22-29. https://doi.org/10.35609/gjbssr.2020.8.1

7) Villalino, N. A. P., Cagasan, E.G. (2012). Conditions surrounding publication performance of faculty members to two selected higher education institutions in Eastern Visayas, Philippines. Annals of tropical Research. 34(2), 75-95.

https://www.academia.edu/31780071/
8) Vincze, Z. (2010). Grounded theory. In Mills, A. J., G. Durepos, \& E. Wiebe, E. (Eds.). Encyclopedia of case study research, 429-432. Thousand Oaks, CA: Sage.

9) Hussein, M. E., Hirst, S., Salyers, V., \& Osuji, J. (2014). Using Grounded Theory as a Method of Inquiry: Advantages and Disad-vantages. The Qualitative Report, 19(27), 1-15. https://doi.org/10.46743/\%202160-3715/2014. $\underline{1209}$

10) Wassenaar, J. (2006). Publication performance of individual scientists in consolidated versus non-consolidated teams with different team status levels: a survey, Undergraduate manuscript, University of Twente, The Netherlands.

11) Chun Tie, Y., Birks, M., Francis, K. (2019). Grounded theory research: A design framework for novice researchers, SAGE Open Med. 2019, 7. https://doi.org/10.1177\%2F2050312118822927

Citation: Fuentes HC. (2021). Factors influencing faculty publication performance: a grounded theory analysis, Br. J. Arts Humanit., 3(6), 171-176. https://doi.org/10.34104/bjah.02101710176 @ @ 